\title{
İşlevi Kaçma Yoluyla Olumsuz Pekiştirme Olan Problem Davranışların Yer Aldığı Araştırmaların İncelenmesi
}

\author{
Şerife Yücesoy* \\ Anadolu Universitesi
}

\author{
Dilek Erbaş ${ }^{* *}$ \\ Anadolu Universitesi
}

\begin{abstract}
Özet
Problem davranışlar özürlii ve özürlï olmayan bireylerde oldukģa sık görülmektedir. Problem davranıslar bireyler tarafindan istendik bir sonuca ulaşmak için gerçekleştirilirler ve belirli bir işleve hizmet ederler. Bu

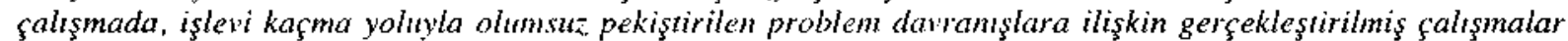
denek, ortam, siire, problem davranıs, veri toplama, test oturumlar, arasturma modeli, güvenirlik, bulgular ve davranış değiştirme teknikleri açısından incelenmiştir. Buna ek olarak, ileri araştırmalara yönelik öneriles sunulmuşfur.
\end{abstract}

Anahtar kelimeler: Problem daıranş̧lar, kaçma yoluyla olumsuz pekiştirilen problem davranşlar. olumsuz pekiştirme, işlevsel analiz

\begin{abstract}
Individuals with and without disabilities display problem behaviors frequently. Problem bellaviors are displayed in order to reach and expected result, and serve a specific function. This study examines the research conducted on problem behaviors, whose function is escape in terms of subjects, settings, duration, problem behaviors, data collection, test conditions, research model, reliability, resulls and behavior changing fechniques. In addition. some suggestions regarding future studies are provided as well.
\end{abstract}

Key words: Problem behaviors, problem behaviors maintained by escape, negative reinforcement, functional analysis.

Günuimüzde, ögretmen. yönetici ve anne babalarn okuldaki önemli sorunlarından birisi öğrencilerin sergiledikleri problem davranış]ardır (Cangelosi, 1993). Problem davranışlar okul ortamlarinda siklıkla önemli sorunlar yaratmaktadır. Problem davranışar ögretmen. yŏnetici ve anne babaların bu davranışları azaltmak için çok fazla zaman ve çaba harcamasına neden olmaktadır. Harcanan zaman ve çabanın yanı sıra problem davranışlar, akademik becerilerin ve uygun davranışların ögrenilımesini. sosyal gelişimi ve etkileşimi de olumsuz yönde etkilemektedir (Chandler ve Dahlquist, 2002).

Bireyler tarafından sergilenen, bireylerin kendilerini veya akranlarmu tehlikeye sokan ve toplumsal yaşama katılımı zorlaştıran davranışlar,

\footnotetext{
* Öğr. Grv. Anadolu Üniversitesi Eğitim Fakültesi Önel Eğitim Biłlümü

** Y̌rd. Doş. Dr. Anadolu Üniversitesi Dil ve Konuşıma Bozuklukları Eğitim. Araştırma ve Uygulama Merkezi
} 
"problem davranışlar" olarak tanımlanmaktadı (Carr ve Durand. 1985). Problem davranışlar ile bireyin içinde bulunduğ ortamdlaki olay ve uyaranlar arasında ilişkiler vardır (Erbaş, 2002). Problem davranışlar, davranış óncesinde ve davranış sontasında gerçekleşen çerresel olay ve uyaranlar tarafından desteklenmekt edir. Problem davranışlar, bireyler tarafından isten pitk bir sonuca ulaşmak için gerçekłeştirilirler ve veliı 'óı işıeve - hizmet ederler. Yani, tüm davranışlar gibi problem davranışlar da bir işleve sahiptir (Chandler ve Dahlquist, 2002; Erbaş, 2002).

\section{Problem Davranışların İşlevleri}

Problem davranışların; a) sosyal ilgi ve dikkat elde etme; problem davranışların başka kişilerin ilgi ve dikkat göstermesi nedenjyle olumlu pekiştirilmesi, b) nesne elde erme; problem davranışların yiyecek, oyuncak ve etkinlik elde etme yoluyla olumlu pekiştirilmeśi, c) duyusal uyaran elde etme; problem davranislar sonucunda görme, işitme ya da dokunma şeklinde duyusal geri bildirimler sağlanması, ve d) kaçma; problem davrantşlar göstererek istenmeyen durumlardan kaçma yoluyla davranışların olumsut pekiştirilmesi şeklinde dört işlevi vardır (Chandler ve Dahlquist, 2002: Erbaş, 2002).

\section{Kaçma Yoluyla Olumsuz Pekił̧̧tirme İşlevi}

Problem davranışların işlevılerinden birjsi kaçma yoluyla olumsuz pekiştirmedir. Bazı bireyler problem davranışları hoșa gitmeyen bir uyaran ya da olaydan kaçmak için sergijlemektedirler (Durand. 1990). Olumsuz pekiştirmede, hoşa gitmeyen davranışöncesi uyaran veya olay stlnulmaz ya da hoşa giden uyaran veya olay bireyin problem davràıısııın ardından ortaından geri çekilir (SulzerAzaroff ve Mayer, 1986). Dolayısıyla, bireyin hoşa gitmeyen uyaran veya olaydan kaçmasi ya da kaçınması, problem davranışı guiçlen dirir ve ileride hoşa gitmeyen bir uyaran sunuldugupda ya da hoşa giden bir uyaran ortamdan çekildi tyinde problem davranţ̧ın gerçekleşme olasilığ jrtar (Durand, 1990; Skinner, 1974).

Örneğin; öğretmen bir öğgrenciye problem

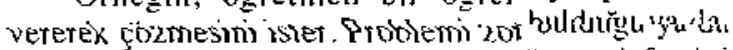
çözmek istemediği için öğrenci bağırır, defterini karalar, defterini yere atar. Öğretrnenin problem çözme isteğini birkaç kez tekrarlaması ve öğrencinin de tepkilerine devam etmesi sonucu ö̆ğelmen öğrenciye: "Sınıftan çık ve dersin sonuna kadar kapının önünde bekle." der. Bu durumda öğrenci saldırgan davranışlar sergileyerek, öğretmenin isteğini engellemeyi ve istemediği etkinlikten kaçmayı öğrenir. Böyle bir örnek olayda davranışın işlevi, kaçma yoluyla olumsuz pekiştirmedir. Bu örneğj davranı̧̧ zinciri içerisinde şu şekilde inceleyebiliriz.

\begin{tabular}{llll}
\hline $\begin{array}{l}\text { Davranı̧ Öncesi } \\
\text { Uyaran }\end{array}$ & Davranşs & $\begin{array}{c}\text { DavrantşSonrası } \\
\text { Uyaran }\end{array}$ & $\begin{array}{c}\text { Davranış } \\
\text { Işlevi }\end{array}$ \\
"Problemi çöz." & $\begin{array}{l}\text { Bağırma, Sınıftan çıkarılma } \\
\text { defterini } \\
\text { karalama ve } \\
\text { yere atma }\end{array}$ & Kaçma \\
\hline
\end{tabular}

Öğrenciler beceriler, etkinlikler, araç geteçler, insanlar, ortamlar ve onlar için hoşa gitmeyen daha başka şeylerden kaçma ya da kaçınma davranışı gösterirler (Carr ve Durand, 1985: Chandler ve Dahlquist, 2002). Kaçma davranışında, öğrenciler hoşuna gitmeyen ya da kendine zor gelen bir etkinliğin devam etmesini engellemek için problem davranış sergilerler. Öğrenciler kaçmayla sonuçlanan kendine zarar verme, araç gereçlere zarar verme, saldırganlık, hırçınlık gibi oldukça yıkıcı ve tehlikeli problem davranışlar sergileyebilecekleri gibi: yönergeleri takip etmeme, katılımı reddetme, etkinliği tamamlamama, farklı etkinliklerle meşgul olma gibi yıkıcı olmayan ve daha pasif biçimde problem davranışlar da sergileyebilirler (Chandler ve Dahlquist, 2002). Ancak, davranış biçimi ne olursa olsun, problem davranışı işlevi kaçma yoluyla olumsuz pekiştirmedir.

Hoşa gitmeyen uyaran ya da olaylar standart değildir. Bir öğrenci için olumlu olan bir uyaran başka bir öğrenci için olumsuz uyaran niteliği taşıyabilit (Chandler ve Dahlquist, 2002). Òrneğin; sınıfta tahtaya yazı yazma etkinliği sırasında gerçekleşen akran ilgisi bir öğrenci için hoşa giden bir uyaran olurken, tahtaya yazı yazarken hata yapmaktan korkan bir öğrenci için hoşa gitmeyen bir uyaran niteliği taşıyabilir (Chandler ve Dahlquist, 2002). Bununla birlikte, bazı ögrenciler

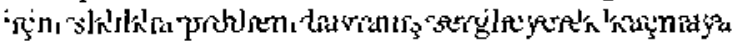
neden olan hoşa gitmeyen uyaranlardan yaygın olanlarını; a) zor olan veya daha önce başartsızlıkla sonuçlanan beceri, araç gereç ve etkinlikler, b) öğcrenci tarafından tercih edilmeyen beceri, araç gereç ve etkinlikler, c) öğrencinin yönettiğj beceri ve etkinliklere karşı ögretmenin yönettiğ beceri ve 
ethınlıkler, d) kullanımı zor olın veya tercıh edılmeyen araç gereçlerle yapılan oğretım, e) yetışkın akran ve aule bureylerınden istenmeyen ılgı veya yetışkın, akran ve aıle bıreylerıyle isenmeyen ethıleşım f) belstlı yerleşım ve oturma duzenı, g) katılım ıçıı gereklı koşullar ve yonergeleı şehlınde suralamak mumkundur (Chandler ve Dahlqust, 2002. Weeks ve Gaylord-Ross 1981)

Kaçma Yoluyla Olumsuz Pekişturme Işlevıne Yonelik Davranış Değiştırme Teknıklerı

Işlevı olumsuz pekıştırme olan problem davruntşların aLaltılması yd da tamamen ortadan kaldırılması ıçın kullanılan davranış değıştırme tekntklerı ıkı temel amaca hizmet eder Bunlar a) problem davranışın ışlevi sle aynı işleve hızmet eden uygun davranışların oğretılmesı ve b) problem davranışın ışlevının değıştirılmesıdı Davranış değıştıme teknıklerını uygulamaya başlamadan once, ışlevı kaçma yoluyla olumsuz pekıştırme olan problem davranışın bağlama uygun olup olmadığı sorusu yanıtlanmalıdır Kaçma davranışının uygun olduğuna karar verılırse, kaçma ışlevıyle aynı ışleve hızmet eden uygun davtanışların oğretılmestne yonelık davranış değışırme teknıklerının kullanımına kaçma davranışının uygun olmadığına kasas verılırse, problem davianısın ışlevını değışırmeye yonelık davranış değıştırme teknıklerının kullanımına kaı verılmelıdı (Chandler ve Dahlquist, 2002)

Kaçma sle aynı Işleve hrzmet eden uygun davranışların oğretılmesıne yonelık davranış değıştırme teknıklerı, a) oğrencıye bır etkınlığe katılmak, araç gereçlerı kullanmath veya akıanlarld etktleşıme girmek istemedigın belırtmek uzere hullanılacak uygun teknıklerı oğretme, b) oğrencıye alternatıf etkınlık, becerı araş gereç kışı veya ortam talebınde bulunmayı oğretıme, c) oğrencıye becerı veyd etkınlıkler arasında uygun mola isteme teknıklerını oğtretme, d) oğrenuye etkım\}k, becerı veya etkıleşını uygun şekılde sonlandırma talebınde bulunm ıyı ợretme şeklınde sısalanabslı (Chandler ve Dahlquist 2002)

Oğretıms aksarmass nedenıyle ką̧ma davranişıyla aynı ışleve hızmet eden uygun davıanışların oğrettlmesı her Laman mumkın olmayabılır Bu durumda haçma ’şlevını değıştımeye yonelıh davranıs değıştırme teknıklerının kullanılması gereklıdı Kaçma 1̧̧levım değ ğştırmeye yonelık davranış değıştıme teknıklers hend işınde farklı teknıkJerı de sçeren dort grup ultinda incelenebulır (Chandler ve Dahlquist 2002)

Bırıncı grupta yer alan davranış değıştırme teknıklerı becerı, etkınlık, araç gereç ve akranlarda değgşılık yapmayı gerektırır ve a) yonerge becrirı etkınltk ve araç gereçlerın guçluk derecesını azaltma, b) becerı ve etkınlıklere ılışıın beklentılerı aLaltına veya becerı ve etkınlıklerın surelerını kısajtma, c) becerı, etkınlık, araç gereç ve akrarilar arasında tercıb yapma firsatı verme, d) becerı, etkınlık ve araç gereçlerı 1 lgı çekıcı hale getırme teknıkJerını ıçerır (Chandler ve Dahlquıst, 2002)

Ikınc grupta yer alan davıanış değışırme teknıklerı, etkınlıklerın gerçekleştıılmesınde ve araç gerę̧lersn kullanılmasında oğrencı başarłoins artirmaya yonelık tehnıklerdir ve a) becerı ve etkınlık sırasında oğrencıye yardım etme b) becerı veya etkınlık sırasinda olumlu ve duzeltıcı donut verme, c) becerıye ve uygun davranışlara ılışkın model olma, d) becerı ve etkınlık oncesınde ıpuçları sunma e) becerı ve etkınlığın tamamlanmasııı pekıştırme, f) katılımı pekıştırme, g) oğrenciye uygun bıçımde yardım istemeyı oğretme (ışlevsel lletışım oğretımı) ve h) ışbırlıkçı grup çalışması veya akran ogretımı sağlama teknıklerınden oluşur (Chandler ve Dahlquist, 2002)

Uçüncu grup davranış değıştırme teknıklerı etkınlık becerı ve araç gereçlen duzenlemeye ılıskın davranış değıştırme teknıklerıdır Bu teknıkler a) becers, etkınlık ve araç gereçlerı değıştırme b) davranıß̧ı zamanlama, c) tercıb edılmeyen becerı ve etkınlıklerın yerıne tercih edılen becerı ve etkınlıklerı kullanma ve katılımı pekışcırme, d) beceıı ve etkınlıkler sırasında mola verme teknıklerını kapsar (Chandler ve Dahlquıst 2002)

Dorduncu ve son grup teknıler sse, a) kendı kendıne kontrolu sağlamak ıçın ışaret ve ıpuçları sunma b) pıoblem davrantşı gormezden gelme c) becerı ve elkınlığı olımlu bıçımde sonlandırıp başarılı yaşantılar sağlama teknıklerınden oluşan genel davranış değışırme tekmıklerıdır (Chandler ve Dahlquist, 2002)

Tuın bu bılgıler ışı̆̆ında bu çalışmanın amacı, davranış değiştirme surecınde gerçekleşiırlen ışlevsel anaiı 2 sonucunda ışlevı kaçma yoluylı olum৬us pekışturme olarak belırlenen problem davianıslasın yer aldığı araştırmaların ıncelenmesıdı Bu ،maç doğrultusunda, Tablo ! de incelenen çalışmalardakı denek sayısı, yaş cınsıvet 
ozur durumu, problem davrınış, verı toplama ortam, sure, araşturma modelt, guvenırlik, davranış ışlevı, test oturumları ve davranış değışııme tekntklerıne yer verılmıştır

\section{Araştırmaların Değerlendirılmesi}

Bu çalı̧̧ma kapsaminda, davránış değışııme surecinde gerçekleştırılen ışlevsel analız sonucunda ı̧̧levi kaçma yoluyla olumsuz pekıştırme olarak belırlenen problem davranışların yer aldı̆̆ araştırmalar gozđen geçırılerek incelenmıştır $\mathrm{Bu}$ çalışmaya a) 1988.2002 yılları arasında, b) "Behavior Modification, Behavioral Interventıon, Education and Treatment of Children, Joumal of Applied Behavior Analysis, Journal of Positive Behavior Interventions, School Psychology Review" dergilerınde yayınlanan, c) hem yalnızca Işlevsel analız uygulanan hem de ışlevsel anulızle bırlıkte davranış değ d) "ıslevsel analı (functional analysıs/expertmental analysıs), kaçma davranışı (escape behavıor), kaçma yoluyla suren problem davranışlar (problem/challenging behaviors maintained by escape), olumsul pekıştırme (negatıve reınforcement) kaçma yoluyla olumsu $\angle$ pekıştırme (negatıve reınforcement by escape)" anahtar sozcuklerı kullanııan çalışmalar dahıl edılmışıtır

Ulaşılan 36 makale, ızleyen bolumde deneklet, ortam, sure, problem davranıs, verı toplama, araştırma modelı, araştırmaları gerçekleştıren kışıler, gưvenırhık verılerı, sosyal geçerlılık, problem davranışların ışlevlerını belırlemek ıçı hazırlanan test oturumları bułgulaı ve davranıs değıştırme teknıklerı açısından değerlendırılmıştrr

Denekler: Araştırmalar incelendığınde, bes araştırma dışındakı tum arıştırmalarda denek sayısının l-3 arasında değışıklık gosterdığı gorulmektedır Araştırmaların 11 'ınde (\%30) bı altısında (\%17) $\mathrm{ka}, 14$ unde (\%39) uç, dordunde (\%9) dort ve dokuz arasında denekle çalışılmıştır Kahng ve Iwata (1998) tarafından gerçekleştırılen bır araştırmada denek sayısının 66 olması ise dikhat çekıuıdır

A raşıtımalardakı deneklerın cınsyyet yaş ozur durumu gibı ozellıklerıne bakıldığında deneklerın $30{ }^{\circ}$ unun (\%34) kadın 59'unun (\%66) erkek olduğu yanı erkek denehlerın sayısının kadın deneklerın sayssinm iks katı hadar oldugu gorulmektedir Araşırmalarda okuloncesı donemden yetı̧̧ knnlığe kadar değışık yaş duzeyınde denekler yer almaktadır 89 denekten 28' ını (\%31) 0.6 yas arasındakı okuloncesı donem çocukları 27 'sını (\%30) 6.12 yaş arasındakı okul çağı çocukları, 12 sını (\%13) 12-20 yas arasındahı ergenler ve $22{ }^{\prime} \sin _{1}(\% 26) 20$ yaş uzerındekı yetışıınler olışturmaktadır Ortaya çıkan tabloya gore, ergen bıreylerle yurutulen araştırmalaı ın sayısının dığer yaş grubundakı bıreylere kıyasla daha duşuk olduğu soylenebulır

Yurutulen araşıımalarda de $\breve{g} ı s ̧ ı$ ozur grubundan bıreylerın yer aldığını, ancak, buyuk bır kıtleyı zıhın ozurlulerın oluşturduğunu soylemek muınkundur Ikı çalışma (\%5) normal gelışım gosteren bıreylerle, 5 çalışma (\%14) oğtenme guçluğu ve gelışımsel gerılık gosteren bıreylerle, 15 çalışma (\%42) hafıf, orta ve ılen derecede zıhın ozurlı bıreylerle, 14 çalışma (\%39) ıse çok ozurlu bıreylerle gerçekleştrruimış̧ır

Ortam re Suire: Problem davranışların değ uygulaması genellıkle bıreylerın bulunduğu ortamla ]lışkılı olarak okul/sınıf, terapı odası. hastane ve bakımew gıbı farki ortamlarda gerçekleştırıl mıştır Işlevsel analız ıçn yapılan araştırmaların 1 l'ınde (\%30) terapı odası, 8'ınde $(\% 22)$ bireylerin yaşadığı bakımevı, 7'sınde (\%19) hastane, 6'sında (\%17) sinif, 2 sinde (\%6) banyo ve farklı ortamlar kullanilmışir Yurutulen 2 araştirmada da $(\% 6)$ (Hagopian Wilson ve Wilder, 2001, Prazza Fisher, Hanley Remick, Contruccı ve Aıtken 1997) ı̧̧levsel analızın gerçekleştırıldığı ortam honusunda bılgı verılmemıştır Verılen oranlarda da gorıilduğu ğbı, ışlevsel analız ıçın çoğunlukla teıapı odası gıb̉, davranışın gerçex́leş̧ı̆g doğaí ortamlar dışında, değışkenlerın daha rahat kontrol alıına alınabılece ğı yapılandırılmış ortamlar tercıh edılmektedır Ancak. bu davranişları surdureb değış̧kenterı belırleyebılmek ıçın bu sureçlerın doğal ortamlarda gerçekleştırılmesı olłukça onemlıdır Bu durum, işlevsel analız draştırmalarınon henuz doğd ortainlara yansımadığını dưşundurmektedır

Araştırmaların bır kısımındo, ışlevsel ạalızın gerçekleştırıldığı ortamın buyukluğu ortamda bulunan araç gereçler ve ortamın ozell $\mathrm{kler}$ konusunda bılgı verılırken, incelenen araşurmaların tamamında bu tur açıklamalar yer almamaktadır (Pracza Hasey, Remick. Contrucci, Aitken 1997, Hagopan, Wtlson, ve Wılder, 2001) Işlevsel analı gerçekleştıılen ortamların basılarında gozlem 
aynasının bulunduğu, gozlemcının denekleri bu aynanın arkasından isleyerek dabranışarı kaydettog uygulamacının ise denekle ayn ortamda bulunduğu makalelerde rapor edılmektedtr (Kuhn, DeLeon, Fısher ve Wılke, 1999, Lallı ve dığerlerı, 1999)

Araştırmalarda, ışlevsel analız surecındekı her bır deney durumunun test edıldığı oturumların sayısı ve suresı hakkinda bilguler de yer almaktadır $\mathrm{Bu}$ bılgılere gore, oturumların genellıkle 5-15 dakıka arasında surduğu gorulmektedır Oturumların sưresı, çalışmaların 19'unda (\%53) 5 10 dakıka arasında, $10^{\prime}$ unda $(\% 28)$ 10-15 dakıka arasında, uçunde (\%8) 15 dakıkanın uzerınde olmuştur Gerçekleştırılen araştımmalardan 4'unde se oturum sayllari ve sureleri hakktnda bijg1 verılmemıştır (Keeney, Fısher, Adelınıs ve Wulder, 2000, Kennedy ve Meyer, 1996, Lallı ve Dığgerlerı, 1999, Miltenberger, Stricker, Garlinghouse ve Koegel. 2001)

Problem Davranıslal Incelenen araştırmalarda, yapılan ışlevsel anahı sonuçlarına gore ışlevı kaçma yoluyla olumsu $\iota$ pekıştırme olan problem davranışlar çeşıtlı davranış değıştırme teknıklerı kullanılarak değıştırılmeye çalışılmıştır Araştırmalarda ele alındn problem davranışlar kendını yaralama, nesnelere zarar verme, saldırganlık ve hırçınlık gıbı davranışlardan oluşmaktadır Çalışmaların 15'ınde (\%41) kendını yaralauna davianışı, 6'sında (\%17) saldırganlık ve hırçınlık, 2'sınde (\%6) nesnelere zarar verme, 2 'sınde (\%6) sınıf ıçı uygun olmay ın davranışlar, 11 'ınde (\%30) kendını yaralama, saldırganlık, hirçınlık, nesnelere zarar verme, basmakalıp davranışlar gıbı davranışların bırlıkte sergılenmesi problem davranış olarak belırtılmıştır

Araştırmaların \%72 sınde problem davranışlar gozlenebılıs bıçımde ıtade edıleıek tanımlanmıştır Ayrıa bu araştumalaıın burı dışında diğ gerlerınde problem davranıs ornekleyen olumlu ve olumsus oınek davrınıışar belırtılmemıştı (Asmus, Wacker Harding Berg Derby ve Koc1s, 1999) Orneğ çalışmada, kafasını vurma, elını ısırma ve p،ımığını emme davranıçları kendını yaralama davranışı, vurmd, ısırıma tekmeleme çındıkleme ve itme davranışları saldırganlık davranısı, oyunc دhJarı fırlatma, nesnelerı raftın aşağgya ıtme ve mobilyaların uzerinde tepınme duvranıları nesnelere Laral verme davraniş olarak caminianmustur
Ve11 Toplama Değerlendırılen araştırına larda problem davranış̧ırın sayısını ve oluşum sıklığını belırtemek amacıyla zaman aralığı kaydı, olay haydı ve anlık zaman ornehtemı kayıt teknıklerı kullanılmıştır Araştırmaların buyuk bur kısmında problem davranışlara ılışkın verrler dız ustu bulgisayas yardımıyla toplanmış, ancak bu surecin nasıl gerçekleştırı]dığıne ılışkın bılgı verılmemıştır

Yurutulen araştırmalarm $8^{\circ}$ inde (\%22) kayıt teknığıne 1lışkın bır bılgı verılmemıştır (Durand ve Carr, 1991, Keeney ve diğerlerı, 2000, Kennedy ve Meyer, 1996, Kuhn, DeLeon, Fisher ve Wilke. 1999, McCord, Thomson ve Iwata, 2001, Plazza, Moes ve Fisher, 1996, Shukla ve Albın 1996, Zarcone, Fısheı ve Plazza, 1996) Ardşturmalar kullantlan vert toplama teknıklerı açısından incelendiğonde, 26 sında (\%72) Laman dralığı kaydı 2‘sınde (\%6) zaman aralığı kaydının yanı sıra oldy kaydı ve anlık Laman orneklemı kaydı kulfanıldığı gorulmektedı Zaman arahğı kayd kullanılan araştırmalarda sure 6,10 ve 15 sanıyelık Laman dılımlerıne bolunmuştur Zaman aralığı kaydı hullanılan 28 çalışmadan $14^{\star}$ unde (\%50) parçalı zaman aralığı kaydı, 9*unda (\%32) butuncul Laman aralığı kaydı, l'ınde $(\% 4)$ hem parçalı hem de butuncul Laman aralığı kaydı kullanılmıs, $4^{*}$ unde (\% 14) ise hangı tur zaman aralığı kaydı kullanıldığı belırtılınemıştır (Hagopıan, Wison ve Wilder, 2001, Lallı ve diğerlerı, 1999, Pıazza, Fisher, Hanley, Remuck, Contrucc: ve Aıtken, 1997, Vollmer, Roane Ringdahi ve Marcus, 1999)

Arastırma Modelı Gerçekleştırılen araştır majarda, ışlevsel analız surecındekı deney durumlarını, dığer bır deyışle gelıştırılen hıpotezlen test etmek uzere tek deneklı araştırma modellerunden donuşumlu uygulamalar modeli ve tersıne çevirme modelının kullanıldiğ gorulmektedır 36 araşırmanın $23^{\prime}$ unde $(\% 64)$ donuşumlu uygulamalaı modelı, 5 sinde (\%/4) tersine çevirme modelı $4^{\circ}$ unde $(\% 11)$ hem donuşum?u uygulamalar modelı hem de tersine çevırme modelı kullanılııştı

Arastarmaları Gerceklesturen Kișıler InceJenen ardştırınaların \%50 sınde araştırmanın hım tarafından gerçekleştırıldığıne ilışkın bılgı verılme $<$ hen \%8'sınde araştırmacı rehberlığınde oğıtetmen, \%10'unda terapıst, \%10'unda dış̧ırmacı rehberhğnde deneklerin anneler ve \%22\%sinde araşlımacıların, araştırmayı yuruttuğu beltrtılmışur Ancak ıncelenen araştırmaların tümunde, araş- 
tırmaya hatılan oğretımen terapıst ve ebeveynlerın çalışmayı yurutızek ıçın eğıtım afıp almadıklarına Ilışkin bilgıye rastlanımamıştrr

Guvenırlık Verılerı Incelenen araştırmaların tumunde oturumlarin en az \%20 sinde veya en az bır aşamasında gozlemcıler arası guvenır]ık verısı toplanmıştır Çalışmalarda guvenırlık verısı toplamak amıcıyla ıkıncı bır gozlemcı gorev almış ve guvenırlık verılerımın nasıl toplandığına ılışkın bılgıler makalelerde rapor edılmıştır Gozlemcıleı arası guvenırlık "goruş bırlığı / goruş bırlığı+goruş ayrılığı $x$ 100" formulu kullanılarak hesaplanmış çalışmalardakı guvenırlık verılerı \%70 ve uzerınde gùvenı\}r bulunmuştur Goslemcıler arası guvenırlığın yanı sıra, 5 araştırmada (\% i4) uygulamacının, ışlevsel andlı surecının test oturumharındakı yonerge verme, çevresel uyaranharı duzenleme davranss oncesı ve davranış sontası uyaranı sunma gibı davranışlarına ılışkın uygulama guventrliğ veriler ortalaması \%95 (\%89-\%100) toplanmış ve yutksek uygulama guvenırlığı bulgusu elde edilmişır (Iwata, Pace, Cowdery ve Miltenberger I994, Lall Vollmer, Progar Wright, Borrero, Danjel, Barthold Tocco ve May, 1999, McComas Hoch, Paoner ve El-Roy, 2000 Steege, Wacker, Cigrand Berg, Novak Reımers, Sasso ve DeRaad 1990, Vollmer Roane Ringdabl ye Marcus, 1999)

Sosyal Gecerlık Incelenen arıştırmalardan sadece burınde (Galensky Mutenberger Strucher Garlunghouse ve Koegel 2001), araşturmada kullanılan davranış değ̣ıstırme teknığ ıne ılışhın olarak sosyal geçerlılık bulgularını toplamak ı̧ıı olçed Lulianimintir $B u$ çalişa dişinda hrçbir çalışmada, problem duvranışın ļ̧levını belırlemek ıçın kullanılan ışlevseł andiı teknığıne ılışkın sosyal geçerlık bulguları toplanmamıştir

Problem Davranıslarm Islevlerını Belırlemek Icun Hazırlanan Test Oturumlalı Pioblem davranışlar ıçın davranış değııstırıne prog̣ramlarını uygulamadan once, serglenmekte olan problem davranışın ışlevın belırlemeh amacıyla ışlevse! değgerlendırme ve işlevsel analız gerçehles tit tlmıştur Işlevsel değerlendırmede, problem davranıslar ıle bunları surduren çevresel değışkenler arasındakı ılışıııı belırlemek ve hrpotecler gelıştırmek usere goruşmeleı ve gozlemles yapilmıs, davranışlarm işlevine vontık hıpotezler gelıştısılamıştır Daha sonıa davranışların ışlevine yonelık olardk gelıştirılen hıpotezler ışlevsel sınalız surecıyle test edılmıştır

Incelenen araştırmalardan bırınde (Galensky, Miltenberger, Stricker Garlınghouse ve Koegel, 200l) sadece işlevsel değerlendırme surecıne yer verılmış ancak, ışlevsel analız gerçekleştırılmemıştır Ayrica Goh le Iwata tarafindan 1994'de gerçekleştırılen araştırmada, ışlevsel analız test durumlarının neler olduğguna ılışkın bılgı verılmemıştır Bu çalışmaların dışında incelen çalışmalarının buyuk bır kısmının ışlevsel analız surecınde en a $ı$, ama çoğunlukla dort test durumu hazıtlanmıştır Bu test durumları geneliıkle, a) nesne elde ederek olumlu pekıştırme, b) ıłgı elde ederek olumlu pekıştırme c) kaçma yoluyla olumsuz pekıştırme ve d) serbest oyun şeklınde (Placza ve diğerlerı, 1997) ya da, d) istekte bulunma, b) ılgı gosterme, c) yalnız bırakma ve d) serbest oyun (Iwata. Dorsey, Slıfer, Bauman ve Rıbman, 1994) şeklinde araştumacılar veya terapıstler tarafından gerçekleştırılmışır (Bakınız Tablo 1)

Bulgular $B u$ çalışanın amacı gerçekleştırılen ışlevsel analız sonuçlarına gore ışlevi kaçma yoluyla olumsu $\angle$ pekıştırme olan problem davranışların yer aldığı çalışmaların incelenmesi olduğg ıçın birhaç araştırmd dişındakı (çoklu işlevı olan davranışları hedef davr unış olarak seçen çalışmalar dışında) tum çalışmalurda problem davranı̧ların ışlevı kaçma yoluyla olumsuz pekıştırmedır Denekler ılgıden, aşırı uyarandan ya da ethınłıktejn problem davranış sergıleyerek kaçına eğılımı gostermektedırleı

Bazı durumfarda problem davranışiarın çoklu ışlevı olabılmektedır (Erbaş 2002) Yurlıtulen araştırmalar ıncelendığınde de 30 çalışmada (\%83) problem davranışların ışlevı yalnızıa kaçma yoluyla olumsuz pekıştırme ıken, 6 çalışmada (\%17) problem davranışların ışlevı kaçma yoluyla olumsuz pehıştırmenın yanı sıra ılgı ve nesne elde etme yoluyla olumlu pekıştırme ya da duyusal uyai dil elde etme seklındedit (McCord Thomson ve Iwata, 2001 Plazza Fisher ve digerlerı 1997 Piazza Moes ve Fisher 1996. Repp Felce ve Barton 1988 Sharle\}, Iwata, Kahng, M Laleskı ve Lerman 1997 Zarcone Fisher ve Piazza 1996)

Problem davransşlarsn kaçmat sşlevlerı Incelendı ğande problem davianısların işlevlerinın çalısmalaıı 1 inde $(\% 27)$ sosyal echıleşımden

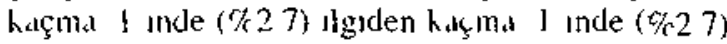


etkınlıkler arası geçışten kaçma 1 inde $(\% 2,7)$ aşııı uy.ruandın (gurultu) kaçma 1 inde (\%2 7) ubbı mudahaleden kaçma 2 sınde (\%55) yemek yemeden haçmı 12 sinde $(\% 33,3)$ etkınlık ya da oğretım etkınlı̆̆ınden kaçma, 14 unde (\%38 8) istenmeyen ya da zor gorevden kaçma olduğu gorulmektedır ancak, problem davranışların ışlevlerının haçınma olup olmadıgına ılışhın bılgıye rastlanılmamışır Çalışıuların 3 unde ıse problem davranış]arın ışlevlerının kaçma olduğu ıfade edılmış hangi uyarandan kaçma olduğu belırtılmemıştır

$\mathrm{Bu}$ verilere gore, deneklerın problem davranışları genellıkle etkınlıkten ya da gorevden kaçmak amacıyla gerçekleştırdığ̆ını soylemek mumkundur

Davrınıs Değıstırme Teknıklerı Incelenen 36 çalısmadan 9 unda (\%25) problem davramşların ışlevını belırlemek ıçın ışlevsel andiı surecıne yer verılmışıı, sıncak herhangı bır davranış değıştırme teknığı uygulanmamıştır Incelenen araşırmaların 27 sınde ıse $(\% 75)$ ışlevsel analı $\angle$ surecı verılerıne daya]ı olarak davranış değıştırme teknığı uyģulan mıştır

Incelenen araştırmalarda kullanılan davranış değıştırme teknıklerı ıncelendığınde çalışmaların 4 unde (\% 14) sonme ve ayrımlı peliştırme, 2 sinde (\%6) sonme ve pekışturme 3 unde (\%8) ı̧̧levsel Jletışım oğretımı, 3'unde (\%8) ayrımlı pekıştırme, ]'inde (\%4) lepkının bedel 7 sinde (\%19) sonme l'inde (\%4) rpucu kullanımi 1 inde $(\% 4)$ ıpucu kullanımı ve ayrımlı pekıştırme 1 inde (\%4) ı̧levsel ıletışım oğretımı ve sonme. 2 sınde (\%6) pekıştirme ve 1'inde (\%4) uygulama paket kullanıldı šs belır]enmıştır

\section{Guvenırlik Çalsşması}

Incelenen çalışmalaıdın 9 u (\%25) ıkıncı

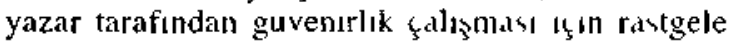
seçılmıştır Seçılen bu çalışmalaı yukarıda belırtılen kategorıler (denek ortam sưre vb) goz onunde bulundurularak incelenmış ve Tablo l’e tekrar yalılmıştır Bu surę̧ gerçekleştırılırken ıkıncı yazar. bırıncı yacarın hazırladığı Tablo l'e bakmamıştır Daha sonrd her ıkı yazałın hazırlamış olduğu Tablo I Incelenerek, mceleme sonuçlarına dayılı olarak guvenırlık hesaplaniasinda gortş̧ bulığı / gorus burlığı + goruş ayrllı̆ı X $100^{\circ}$ formulu hullanılmıştır Guvenulık çalışması sonucunda her bır keltegnriye ılş̧ ın guventrlık

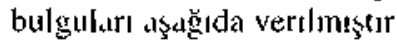

Çalışınanın guvenırlık bulguları denekler ıçın $\% 100$, ortam ıçın \%100, sure ıçın \%100 problem davranıs ıçın \%100, verı toplama ıçın \%98, araştırm. modelı ıçı \% 99 , ışlevsel analız surecınde kullanıłın ışlev belırleme teknıklerı ıçın \%]00, guvenıriık bulguları ıçı \% $\% 00$, davranış değıştırme teknıklerı ıçı \%95 bulunmuştur

\section{Sonuç ve Oneriler}

Bu çalışma kapsamında ıncelenen 36 çalışınada problem davranıçlar ıçın davranış değgştırme programı uygulamadan once 1şlevsel analız yapılmış ve kullanılacak davranış de ğıştırme teknıklerı ışlevsel analız sonuçlarına gore yant verıye dayalı olarak seçılmıştır Işlevsel analız sonuçlarına gore davranış değış̧ırme teknıklerının seçrlmış olması ıse, çalışmaların çoğunda teknıklerın problem davranışların değgıştırılmesınde ethılı olmasına katkı sağlamıştır (Vollmer Marcus ve Ringdahl 1995) Dolayistyla, davranis değıştıme programlarını uygulamadan once ışlevsel değerlendırme ve ışlevsel analı yapılmasının ve kararların verıye dayalı olarak verılmesının bır gereklılık olduğunu soylemek mumkundur Orneğın bır oğrencıntn etkinlıkten kaçmak amacı) la serg!ledığı problem davranışların ış]evının kaçma yoluyla olumsuz pekıştırme olduğunı bılmedığımızde, mola uygulamamı problem davranış azaltmak yerıne arttırabılecektır

Incelenen araştırmaların pek çoğunun oldukça ıyı planlanmış ve yurutulmuş olduğu gorulmektedır Buntunla bırlıkte ıncelenen araştırmalırın bırınde ışlevsel değerlendırme gerçekleştırılıp gerçekleştırılmedığı̆ıne, gerçekleştırıldıyse nasıl grerçekleş turldigine uliskin bilgilere yer verilmemiştir Işlev sel değerlendırmenın yını sıra bazı çalışmalarda ışlevsel ،nalı<ın nıı১l] gerçekleştırıidığı de ayrıntıl bır şekılde açıklanmamıştır $\mathrm{Bu}$ durum araş tırmaların yınelenebılıtlıgın azaltmaktadtr Yuıutulecek araştırmalarda Işlevsel değerlendırme ve ışlevsel analı sureçlerıne daha kaps.mblı bır şekılde yer veritimelıdır

Denek sayıları açısından bakıldığında araştırmaların \% 77 gubı oneml bolumunun bır veya ıkı denekle gerçehleştırıldı ğı gorulmektedır AraşIIrmalardakı denek sayılarının dz olması draştırmaların dış geçerlığını yanı, genellenebılırlı̆̆ıı olumsuz yonde etkilemehtedir Ayrica, araştı maların balılarında denek ocellıklerıne ılışkın ayrıntılı bıtgının verılmemest de yınelenebilırlı̆̆ azaltmaktadır Ileride yurutulecek araştırmalara 
yonelık, denek ozellıklerıne ı̉ışıı bılgılerın daha ayruntılı olması onerılebılır

12-20 yaş arasındakı ergen bıreylerle ve normal gelışı gosteren bireylerle yurutulen d̊dştırmaların sclyısının az olmałı dıkkat çekıcıdır Araştırma bulgularının genellenebılırlığını artturmak amaciyla, ergen bireylerle ve normal gelışım gosteren bıreylerle gerçekleşırılecek araştırmalara gereksınım duvulmaktadır

Araştırmalarda ele alının problem davranışlar sınıf ve ev gıbı doğal ortamlarda oluşan davranışlardır Ancak, bu çalı̧̧mal arda ı̧̧levsel analız ıçın çoğunlukla doğal ortamlar yerıne yapilandırılmış ortamlar kuilanılmıştır Oysa doğal ortamlarda gerçekleştırılen ışlevsel analıze ılışkın araştırma bulgularına gereksınım duyulmaktadır Buradan yola çıkarak ışlevsel anclızın doğal ortamlarda gerçekleştırıleceğı veya doğal ortam larda ve yapılandırıltmış ortanılard، gerçekleştırılen ışlevsel analı bulgutarının karş̧laştirilacd ğ araştırmalar desenlenebılır (Erbaş, 2001)

Uzerınde durulması gereken onemlı noktalardan bırı, ışlevsel analıL surecının kım tarafından gerçekleştırıldığıdır Çalışmaların çoğunluğund d davranış değıştırme programının hımın tarafından uygulandıgı belırtılırken bırkaç çalışma dışındakı (Lallı, Kates ve Casey, 1999, Lallı ve dığerlerı, 1999) çalışmalarda ışlevsel anaIızın kımın tarafından gerçekjeştırıldığı belırtılmemışı Yurutulecek araştırmalarda işlevsel değerlendırme ışlevsel analız ve davıınıs de ğıştırme programının kımın tarafından gerçekleştırıldığı ve bu kışılerın ozellıklerı ıle ılgılı kapsamlı bılgı verılmesı araştırmaların yınele nebılırlığını arttıracağı gıbı elde edılen verılerın geçerlığı ve guvenırlığı açısından dd oldukça onemlıdır

Incelenen araştırmaların tumüunun ışlevse! analız surecinde gózlemciler arası guvemulık verisı toplanrken, yalnıcd $5 \mathrm{~mm}$ (\%14) sşlevsel analı surecınde uygulama guvenırlığı verısı toplanmış, 31 araşıırma (\%86) gıbı buyuk bı bolumunun ışlevsel analız surecınde uygulama guvenırlığı veiss toplanmamıştır Oysa, ışlevsel anılız sureconde uygulamacının test durumları dışındahı tum de ğ sışkenlerı kontrol altına alsp almadığın belırlemek ve uygulamacinin test otusumlarin ne derece guvenılır uyguladığın belıriemek usere uygulama guvenurlığ verıs foplamak gerehmektedı Dolayısıyla, davrını değıı̧tırme programının vanı sıra ışlevsel analıL surecındekı test oturumlarında da uygulama guvenırlığı verılerının toplanacağı araştırmalar desenlenmelıdır

Galensky ve diğerlerı tarafından 2001 de gerçekleştırılen araştırma dışında, ıncelenen dığer ardştırımalarda problem davranışların ışlevlerını belırlemek ıçn kullanılan ışlevsel analız tek nıklerıne ılışkın sosyal geçerlık verılerı toplan mamıştır Ancak, ışlevsel analız surecının uygu lamacilar tarafindan nasıl algılandiğı ve bu surecin araşııma dışında kullanıp kullanılmayacağını belırlemek içın sosyd] geçerlık bulguların toplanması oldukça onemIıdır Dolayısıyla, ışlevsel analız surecının gerçekleştırı]dığı araştırmalarda sosyal geçerlık verılerının toplanması onerıl mektedır

Incelenen araştırmalarda uygulanan davranış değıştırme teknıkletının genellıhle ıtıcı uyaran ıçermeyen davranış değışı̆ıme teknıklerı oldugu gorulmektedır Davranış degrştirme tehnığt uygulanmadan once hedef davranışın işlevinun belırlendığı ışlevsel analız uygulamasına yer verılmış oinıası ışleve uygun davranış değışıtırme teknıklerıntn seçılmesını sağlamıştır Boylece ıtıcı uyaran ıçermeyen davranıs degışıtırme teknıklerıne yer verılmıştır

Incelenen çalışmalarda ışlevsel analıze dayalı davranış değıştırme uygulamalarının etkılılığı le dığer yollar hullanılarak (orneğın problem davranışın şeklıne gore yd da hangı problem davranışlarda hangı teknıklerın daha sık kullınıldığına ılışkın olarak gerçekleştırılen çalışmalar ıncelenerek) seçılen davranış de ğışuturme uygulamaIarının etkılılıklerıne ılışkın karşılaşiırmalı çalışmıların olmadıgı belırlenmıştır Dolavısıyla, ışlevsel analıze dayalı ve dayalı olmadan seçılen davranış değıştırme teknıklerının etkılılıklerını inceleyen araştırmalar desentenebilır

Incelenen arıştırmalarda hedef das ranış olarak seçılen problem davranı̧lar incelendı ğınde genellıkle kendını yaralama ve saldirgan davranışlar gıbı ağır problem davranışların seçıldığı gorulmektedır, oysa, sozel yonergelerı yerıne getırmeme, sinıt kurallarına uymama sinifta gezınme gibı bazı hafıf sayılabılecek problem davranışlara yonelık çalışmalar da desenlenebıı ır

Bu çalışma, davranıs de ợştırme surecınde gerçekleştırtlen ışlevsel analız sonucunda ışlevı olumsu 2 pekıştırme olarak belılenen problem davranışların yer aldığı 36 araştırmanın gozden 
geçırılerek ıncelenmesıyle ınırlıdır Bu çalışmadan yold çıkarak. a) ışlevı olumlu pekıştırıme veya duyusal uyaran elde etme olan problem davranışların yer aldığ araştırmalar. b) basmakalıp davranışlar gıbı farhlı problem davranı̧̧ ların yer aldığı araştırmalar ve c) atle ıle gerçekleştırılen ışlevsel analız uygulamalarının yer ،ddığı çalışımalar ve (d) doğal ortamlarında gerçekleştırılen ışlevsel anılız uygulamularının yer aldığı çalışmalar Incelenebilır

Tablo 1: Islev Olumsuz Pekıştıme Olan Problem Davanışlam Yer Aldı̆̆ı Araştumalar

\begin{tabular}{|c|c|c|c|c|c|c|c|}
\hline Kaynak & Denek & Yaş & Cinsivet & $\begin{array}{c}\text { Oxur Durumu } \\
\text { Sayıs }\end{array}$ & ['roblem Davranı̧ & Verı T oplama & Or1am \\
\hline $\begin{array}{l}\text { MuCormels Goddand } \\
\text { Hoch } 2002\end{array}$ & $\mathbf{I}$ & 9 & Erkek & Ogreime gucluğ & $\begin{array}{l}\text { Nesnelere z иar } \\
\text { verme }\end{array}$ & 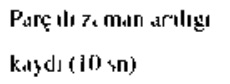 & Okul\& \\
\hline $\begin{array}{l}\text { McCord \&witct G ılensky } \\
\text { Ellıngson \&Thomvon, 200] }\end{array}$ & 2 & 4143 & $\mathrm{~K}$ Idın (2) & $\begin{array}{l}\text { lleriderecede Lihın } \\
\text { orurlu oustık }\end{array}$ & $\begin{array}{l}\text { Kendıni yuralama } \\
\text { nesnelere zarar verme }\end{array}$ & 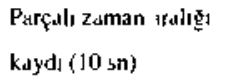 & Bakmmevı \\
\hline $\begin{array}{l}\text { Hagopian Wilson \& } \\
\text { Wilder } 2003\end{array}$ & $\mathbf{I}$ & 6 & Erkek & $\begin{array}{l}\text { Hutif derecede } 71 \text { hin } \\
\text { ozurrliu olistik }\end{array}$ & $\begin{array}{l}\text { Kendinı y uralanıı, } \\
\text { sidırgunlık }\end{array}$ & 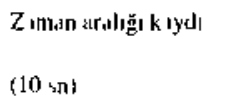 & - \\
\hline $\begin{array}{l}\text { G.lenky Milientier, Stricker } \\
\text { Garlinghouse \& Kowgei } 2001\end{array}$ & 3 & 357 & $\begin{array}{l}\text { Erkek (1) } \\
\text { Kadın (2) }\end{array}$ & $\begin{array}{l}\text { Normil gelıșm } \\
\text { goveren çou.uklut }\end{array}$ & $\begin{array}{l}\text { Hırł̧ılık } \\
\text { 3eneyı reddetmlek }\end{array}$ & 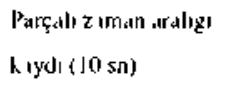 & Bakımevı \\
\hline $\begin{array}{l}\text { Roberts Marshall Nelion } \\
\& \text { Albers } 2001\end{array}$ & 3 & 710 & Erkek (3) & $\begin{array}{l}\text { Normal geiışm } \\
\text { gosteren çocukl ır }\end{array}$ & $\begin{array}{l}\text { Sun1f ıçı uygun } \\
\text { olnily tn da rantşlar }\end{array}$ & $\begin{array}{l}\text { Parç ilı Zaman aralığı } \\
\text { kaydı (ci0 sn) }\end{array}$ & Okul \\
\hline $\begin{array}{l}\text { Me Cord Thomson } \\
\& \text { I } w+2001\end{array}$ & 2 & 2738 & Erkek (2) & $\begin{array}{l}\text { Jleri derecesde zhon } \\
\text { apurlu }\end{array}$ & Kendmu yaraldma & - & Bakınevi \\
\hline $\begin{array}{l}\text { McComas Hoch } \\
\text { Pstone \& CI Roy } 2000\end{array}$ & 3 & 8,89 & Erkck (3) & Gellisimbel gerilith & $\begin{array}{l}\text { Neinelere zarir } \\
\text { verme }\end{array}$ & 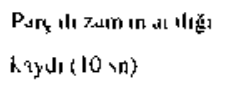 & Ohul \\
\hline $\begin{array}{l}\text { Keeney Fisher } \\
\text { Adeluns \& Wilder } 2000\end{array}$ & 1 & 33 & Kaldın & $\begin{array}{l}\text { Ileri derecede } \angle \text { llun } \\
\text { ozurlu }\end{array}$ & $\begin{array}{l}\text { Kendinı varalama } \\
\text { valdrs zanlık }\end{array}$ & {[} & Bakınevı \\
\hline $\begin{array}{l}\text { Kumu Wacker Hatrding } \\
\text { Burk. Derbu \& Kouls } 1999\end{array}$ & 3 & 345 & Lrkeh (3) & $\begin{array}{l}\text { Orta derectde sikun } \\
\text { ozurlus }\end{array}$ & $\begin{array}{l}\text { Kendin yaral tma } \\
\text { uldergunlik: } \\
\text { cetreyc zorar verme }\end{array}$ & 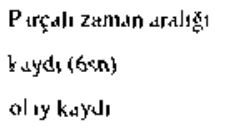 & Farklı ort \\
\hline $\begin{array}{l}\text { I lli Voptmer Piog ir Wright } \\
\text { Bortero Dinsel Barihold } \\
\text { Touco \& Muy } 1999\end{array}$ & 5 & $\begin{array}{l}3910 \\
1821\end{array}$ & Erkeh (5) & $\begin{array}{l}\text { Hatil we ilen derecede } \\
\text { ghin orafill otlstak }\end{array}$ & Kendinı yaralama & $\begin{array}{l}\text { Zam ind als k iydi } \\
\text { [ ] } 0 \text { (N) }\end{array}$ & $\begin{array}{l}\text { Terspi } \\
\text { Od IsI }\end{array}$ \\
\hline $\begin{array}{l}\text { tollmer Roune Ringdini } \\
\text { \& M usแ৬ } 1999\end{array}$ & 3 & 41617 & $\begin{array}{l}\text { Erkeh (2) } \\
K \sin (1)\end{array}$ & $\begin{array}{l}\text { liers derece zihen } \\
\text { opitulu beck nuei oztriu }\end{array}$ & $\begin{array}{l}\text { Kendinı yar il uma } \\
\text { sidlirganlik }\end{array}$ & 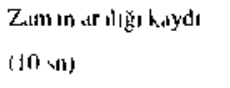 & $\begin{array}{l}\text { Terapl } \\
\text { odal }\end{array}$ \\
\hline $\begin{array}{l}\text { Cooper Wacker Brown } \\
\text { MeComis Peak Dreu } \\
\text { A.mus \& K lycer } 1499\end{array}$ & 4 & 35 & $\begin{array}{l}\text { Erkeh (1) } \\
\text { K idin (3) }\end{array}$ & Gelnimsel gerthk & Hırçıiluk & 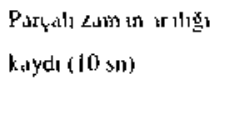 & $\begin{array}{l}\text { Hastane } \\
\text { iervisi }\end{array}$ \\
\hline I ،llı Kalk \& Se.ıl 1999 & $?$ & 1011 & Hexheh (?) & 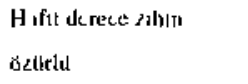 & S.iddirgsinlik & 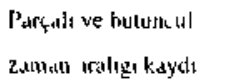 & $\begin{array}{l}\text { Hastane } \\
\text { stmí }\end{array}$ \\
\hline
\end{tabular}




\begin{tabular}{|c|c|c|c|c|c|}
\hline Sure & $\begin{array}{l}\text { Iraştırına } \\
\text { Vodelı }\end{array}$ & Guvenitlık & Dasrants lşleu & Test Oturumbaru & $\begin{array}{l}\text { Davranıș Degışı̀mı } \\
\text { Tekntı̆i }\end{array}$ \\
\hline $10 \mathrm{dk}$ & $\begin{array}{l}\text { Dónuşıimlu } \\
\text { uygulımalar modelı }\end{array}$ & $\begin{array}{l}\text { Gozlemuler if } \\
\text { guvenirlık }\end{array}$ & Eth nlikten $k$ tุ mi & $\begin{array}{l}\text { Ilgi elue eime ih tJe mik isteh } \\
\text { osun }\end{array}$ & Sonme+pek st nme \\
\hline $10 \mathrm{dk}$ & 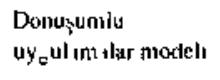 & $\begin{array}{l}\text { Gorlenicsicr dr y } \\
\text { guvenuthik }\end{array}$ & 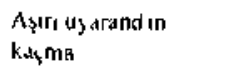 & $\begin{array}{l}\text { Guruitú ech less node bulunmanit } \\
\text { oyun }\end{array}$ & $\begin{array}{l}\text { Sọnmctayrımıiı } \\
\text { pekıştıme }\end{array}$ \\
\hline \multirow[t]{2}{*}{\lrcorner $0 \mathrm{dk}$} & $\begin{array}{l}\text { Donusumlu } \\
\text { uyguls mal is modelı }\end{array}$ & $\begin{array}{l}\text { Gozlemcler arasi } \\
\text { guveniclk }\end{array}$ & Jlgiken kaçmad & 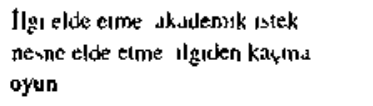 & $\begin{array}{l}\text { dşlewcel Jelism } \\
\text { ofretım! }\end{array}$ \\
\hline & & $\begin{array}{l}\text { Goriemciler arasi } \\
\text { gavenirish }\end{array}$ & $\begin{array}{l}\text { Yemek yemeden } \\
\text { kuç max }\end{array}$ & + & $\begin{array}{l}\text { Sonmectdyrımlı } \\
\text { pekrștıcme }\end{array}$ \\
\hline $15 \mathrm{dk}$ & $\begin{array}{l}\text { Donusitumlu } \\
\text { us gulumal ir nodede] }\end{array}$ & $\begin{array}{l}\text { Gozlemuler ar sl } \\
\text { idvenurl h }\end{array}$ & 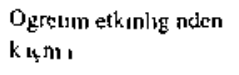 & $\begin{array}{l}\text { Ogreumel ethinlik engelleyk } \\
\text { etkinl } k \text { sheldenuth olm tydn eth nlih }\end{array}$ & Uystul ניחו \\
\hline $5 \mathrm{dk}$ & $\longrightarrow$ & $\begin{array}{l}\text { Gozlemeiler ar as } \\
\text { guvenirlih }\end{array}$ & $\begin{array}{l}\text { E-kınlikter arass } \\
\text { geţışten kiçms }\end{array}$ & 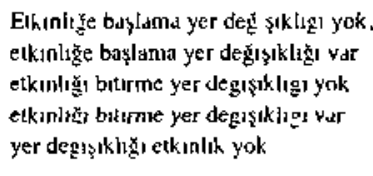 & $\begin{array}{l}\text { Sönme+ıytımlı } \\
\text { pekıştırme }\end{array}$ \\
\hline $1015 \mathrm{dk}$ & $\begin{array}{l}\text { Dobușomlú } \\
\text { uygulamulur modelı }\end{array}$ & $\begin{array}{l}\text { Gozlemchler arası } \\
\text { zuvenırdsk } \\
\text { uyguiamd guvenirlıg }\end{array}$ & $\begin{array}{l}\text { Oğretım etkmlilı indkin } \\
\text { kuç̧na }\end{array}$ & $\begin{array}{l}\text { Ilgi elde einje nesne eluc etme } \\
\text { dk klemik isleh oyun }\end{array}$ & Ipucu hullsuımr \\
\hline$\ldots$ & $\begin{array}{l}\text { Donişumilu } \\
\text { uygulam ilar model }\end{array}$ & $\begin{array}{l}\text { Gozlemciler ar isı } \\
\text { guvenrsth }\end{array}$ & Goreviden k içm। & $\begin{array}{l}\text { ligı elde elme ahademih istek } \\
\left.y^{3}\right] \mathrm{m} z \text { burdkılma oyon }\end{array}$ & Tephmin bedelı \\
\hline $5 \mathrm{dk}$ & $\begin{array}{l}\text { Dónușimlumlu } \\
\text { uygulamal ir modelı }\end{array}$ & $\begin{array}{l}\text { Gózlemciler arası } \\
\text { guve urlih }\end{array}$ & Görevden kuçm । & $\begin{array}{l}\text { litilelde } t \text { tme Ikadermik wlek } \\
\text { ojun }\end{array}$ & Uygulamat pakeiı \\
\hline- & $\begin{array}{l}\text { Dónḋșumilıt } \\
\text { uygulamalar modelı }\end{array}$ & $\begin{array}{l}\text { Gozkernuiler drdsı } \\
\text { gusenirlih } \\
\text { uygul ıma Luvenirligı }\end{array}$ & Goreviden kaçma & $\begin{array}{l}\text { Ila elde etme nesne ckle elme } \\
\text { dkudemik siek yalniz birakılma } \\
\text { kontrol durumu }\end{array}$ & 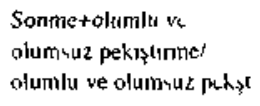 \\
\hline $10 \mathrm{dh}$ & $\begin{array}{l}\text { Dönuşumlí } \\
\text { uygulamal tr modelı }\end{array}$ & $\begin{array}{l}\text { Gozkmuller aris } \\
\text { suventrik } \\
\text { uygul ins uvenirigg }\end{array}$ & Gortıden kıৎ̧md & $\begin{array}{l}\text { ligı elde etme neshe elde etme } \\
\text { dkademık tsiek sonuç vermicme } \\
\text { kontrol durumu }\end{array}$ & Aynnalı pek slitme \\
\hline 240 तh & $\begin{array}{l}\text { Tersme çe: urme } \\
\text { modelı }\end{array}$ & $\begin{array}{l}\text { Gozlenuller ar is } \\
\text { gusenirth }\end{array}$ & $\begin{array}{l}\text { Yomeh yemeder } \\
\text { hism: }\end{array}$ & $\begin{array}{l}\text { Tercih ed leat yyecek } \\
\text { tercih edilneyen yisecek }\end{array}$ & $U_{\text {ygul Ima yok }}$ \\
\hline, $10 \mathrm{dk}$ & - & $\begin{array}{l}\text { Goblenicilet if } 14 \\
\text { guvenirlih }\end{array}$ & $\begin{array}{l}\text { Lunmejen sorevden } \\
h x_{\mathrm{r}} \mathrm{nl}\end{array}$ & Ohuma jazm \& minemitih & Uyguul ima yok \\
\hline
\end{tabular}


YER ALDIGI ARAŞTIRMALARIN INCELENMES!

\begin{tabular}{|c|c|c|c|c|c|c|c|}
\hline Kaynak & $\begin{array}{l}\text { Denck } \\
\text { Sa\}।aı }\end{array}$ & Yaş & Cinsiyet & Oeur Derum & Problem Darrams & $\begin{array}{l}\text { Verı } \\
\text { Toplama }\end{array}$ & Ortant \\
\hline O Reilly \& Linumonl 1949 & 2 & 831 & $\begin{array}{l}\text { Erkek (I) } \\
\text { K tdin (1) }\end{array}$ & $\begin{array}{l}\text { Down Sendromu } \\
\text { lert d recede gorine } \\
\text { ozürlid }\end{array}$ & $\begin{array}{l}\text { Suldirganlık } \\
\text { kendıni ydralamá }\end{array}$ & $\begin{array}{l}\text { Parçult zam sn ar.alıg। } \\
\text { kaydı }(10 \text { sn) }\end{array}$ & $\begin{array}{l}\text { Terapl } \\
\text { odasi }\end{array}$ \\
\hline $\begin{array}{l}\text { Kuhn DeLeon Fisher } \\
\& \text { Wilke } 1999\end{array}$ & I & 35 & Erkek & $\begin{array}{l}\text { Jlers derecede zilin } \\
\text { ozurlu otisitk }\end{array}$ & Kendın yur ilama & $\begin{array}{l}\text { Zaman aral|gı k 1ydı } \\
\text { (10 sin) }\end{array}$ & $\begin{array}{l}\text { Terapı } \\
\text { oday }\end{array}$ \\
\hline $\begin{array}{l}\text { Cor Huneld Austun } \\
\text { \& Bulcy } 1998\end{array}$ & 1 & 33 & Kadun & $\begin{array}{l}\text { llerı derecede zihun } \\
\text { ozírlu }\end{array}$ & Saldirganlik. & $\begin{array}{l}\text { Butumul <ath in ar thext } \\
\text { krydi }(10 \mathrm{sn})\end{array}$ & $\begin{array}{l}\text { Bakwmevis } \\
\text { mutfish }\end{array}$ \\
\hline Kulln $n_{\varepsilon} \&$ Iualt 1998 & 66 & - & - & Than ozurlo & Kendint y Iral $2 m a$ & 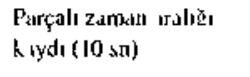 & $\begin{array}{l}\text { Terapl } \\
\text { odds }\end{array}$ \\
\hline $\begin{array}{l}\text { Richplun Wacker Asmus } \\
\text { \& Civey } 1998\end{array}$ & 1 & 27 & Erkek & $\begin{array}{l}\text { Ilerı derecede /hin } \\
\text { otirlu ol'sik }\end{array}$ & $\begin{array}{l}\text { Saldırge inlik } \\
\text { p irmak emme }\end{array}$ & $\longrightarrow$ & Hastane \\
\hline $\begin{array}{l}\text { Plazzd } \Gamma_{1} \text { sher } \mathrm{H} \text { inle\}, } \\
\text { Reminh Contruces } \\
\text { \& Aitken } 1997\end{array}$ & 3 & 789 & $\begin{array}{l}\text { Erkek (2) } \\
\text { Kidin (1) }\end{array}$ & $\begin{array}{l}\text { H dit Jereced zilun } \\
\text { ozilrlu serubral palsy, } \\
\text { hoperahtivite }\end{array}$ & S Iklire inlik & $\begin{array}{l}\text { Parçalı Zıının arslı̌̆ı } \\
\text { kaydı }(15 \mathrm{rn})\end{array}$ & - \\
\hline $\begin{array}{l}\text { Shirley iw id Kuting } \\
\text { Mazaleski \& Lerman } 1997\end{array}$ & 3 & $\begin{array}{l}7429 \\
39\end{array}$ & $\begin{array}{l}\text { Erkek (2) } \\
\text { Kadtn }(1)\end{array}$ & $\begin{array}{l}\text { Iicri derucede zinın } \\
\text { ozurlu }\end{array}$ & Kendımı yar ılanza & $\begin{array}{l}\text { Parçala zantun) aralıl } \\
\text { Kaydu (10sn) }\end{array}$ & Bakınevi \\
\hline PI tzבd Moes \& Hisher 1996 & 1 & 11 & Erkek & $\begin{array}{l}\text { H ifil derecede ? In } \\
\text { ofurlu otssik }\end{array}$ & $\begin{array}{l}\text { Kendini yafal amad } \\
\text { silderganlik }\end{array}$ & - & Hasladile \\
\hline Kennedy \& Meyer 1996 & 3 & $\begin{array}{l}1315 \\
18\end{array}$ & $\begin{array}{l}\text { Luhek (?) } \\
\text { Kadin (1) }\end{array}$ & $\begin{array}{l}\text { Orta ve ileri dikrecede } \\
\text { zilhn ozurlu }\end{array}$ & $\begin{array}{l}\text { Kendın yaralanis } \\
\text { wa dirgetnik }\end{array}$ & 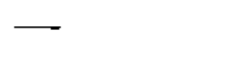 & Sinif \\
\hline $\begin{array}{l}\text { Zarcone Tisher } \\
\text { \& Plazza } 1996\end{array}$ & 1 & 10 & Erhek & 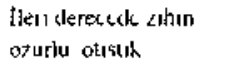 & Duzem bozmad & - & Hastałle \\
\hline Shukli \& Albin 1946 & s & 19 & Erkech & $\begin{array}{l}\text { Hern duzeyde } \\
\text { gelişmimsel gerilih }\end{array}$ & $\begin{array}{l}\text { Kendım yar tham } \\
\text { sidere inlok }\end{array}$ & - & B (kstyev) \\
\hline Vollmer \& Northup 1996 & 3 & 4811 & Erkeh (3) & $\begin{array}{l}\mathrm{OI} \text { I } \\
\text { ecrilit. }\end{array}$ & Hır̨ylntth & 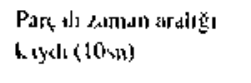 & Hastape \\
\hline $\begin{array}{l}\text { Vollmar Mircus } \\
\& \text { Rmgedi|ll 199, }\end{array}$ & 2 & 418 & Crhek & $\begin{array}{l}\text { Jers derecede zihin } \\
\text { orturlu otistik }\end{array}$ & Kenclimi yaralatut $t$ & 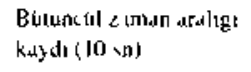 & $\begin{array}{l}\text { Ter ip! } \\
\text { oduri }\end{array}$ \\
\hline
\end{tabular}




\begin{tabular}{|c|c|c|c|c|c|}
\hline Sure & $\begin{array}{l}\text { Araşuruma } \\
\text { Modelı }\end{array}$ & Guvenirlsh & Davranı̧ Işlev] & Test Oturunoları & $\begin{array}{l}\text { Davranış Dugışı̆ır } \\
\text { Teknıgı }\end{array}$ \\
\hline $5 \mathrm{dk}$ & $\begin{array}{l}\text { Tersıne çeu Ime } \\
\text { models }\end{array}$ & $\begin{array}{l}\text { Gòzleniclet all ast } \\
\text { guvenirlik }\end{array}$ & Görevden kaçma & $\begin{array}{l}\text { Il } 1.1 \text { elde etme nesne elde etme } \\
\text { al idemek } 1 \text { led oyim }\end{array}$ & Uygulama yok \\
\hline $10 \mathrm{dk}$ & $\begin{array}{l}\text { Dónuşitmlì } \\
\text { uyģulumalar modelı }\end{array}$ & $\begin{array}{l}\text { Gozlemuler 7rast } \\
\text { guscnurlik }\end{array}$ & Gorevden kaçnud & $\begin{array}{l}\text { Ilgı elde elme akadem h Nek } \\
\text { y ilnuz birdhilma oyum }\end{array}$ & Sonme \\
\hline $1015 \mathrm{dk}$ & $\begin{array}{l}\text { Donḑ̧umlu uyģulamai } \\
\text { ve lersıne çevirme } \\
\text { modelı }\end{array}$ & $\begin{array}{l}\text { Gozlemulier ar \& } \\
\text { gusenuritik }\end{array}$ & C(kı)ilikięn kaçma & 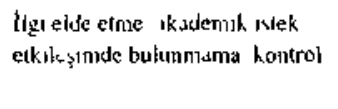 & Uygulaund yok \\
\hline $10 d \mathrm{k}$ & $\begin{array}{l}\text { Dönuşumld uygulamal } \\
\text { ve thrsine çevirme } \\
\text { mandelı }\end{array}$ & $\begin{array}{l}\text { Gozlenusler ar :u } \\
\text { gúvenurlik }\end{array}$ & 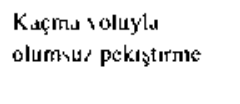 & 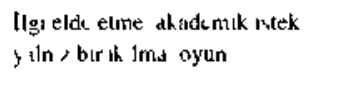 & Uygulamia yok \\
\hline $10 \mathrm{dk}$ & $\begin{array}{l}\text { Donuşumlu } \\
\text { uygui ımular modelı }\end{array}$ & $\begin{array}{l}\text { Gozhemciler drass } \\
\text { gurenurlik }\end{array}$ & Goruvdien kaçma & $\begin{array}{l}\text { Ilgr elde eime akudemuk istek } \\
\text { yalniz birskilms oyun }\end{array}$ & Sunme \\
\hline $10 \mathrm{dk}$ & $\longrightarrow$ & $\begin{array}{l}\text { Gozlemulter wrost } \\
\text { guven rith }\end{array}$ & 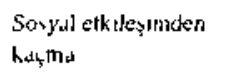 & $\begin{array}{l}\text { Ilgi elde etme nesne elde ktme } \\
\text { akademuk wek oyun }\end{array}$ & 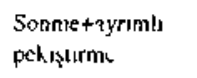 \\
\hline 15 dh & 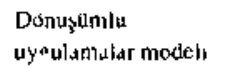 & $\begin{array}{l}\text { GoLlemuler arasi } \\
\text { gutemilik }\end{array}$ & Kaçma & 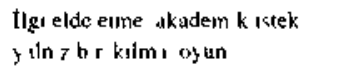 & $\begin{array}{l}\text { [şlevse] Ilețọm } \\
\text { oģrettum }\end{array}$ \\
\hline $10 \mathrm{dk}$ & $\begin{array}{l}\text { Donușumlu } \\
\text { uygulam tlat modelels }\end{array}$ & $\begin{array}{l}\text { Gozlemciler aldss } \\
\text { givivenurlih }\end{array}$ & K ıฺ̧̧াম & $\begin{array}{l}\text { Ilgı elde etme ak ıdemik istek } \\
\text { yulnız burakılm । oyun }\end{array}$ & 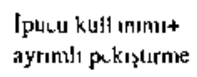 \\
\hline 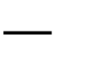 & $\begin{array}{l}\text { Dönuşumlu } \\
\text { uyggulamalar modeti }\end{array}$ & $\begin{array}{l}\text { Gozlemiciler drátl } \\
\text { gi venurlik }\end{array}$ & $\begin{array}{l}\text { O rut|m ethinl \& gulen } \\
\text { halymid }\end{array}$ & 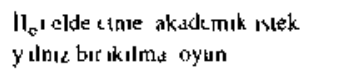 & Uygul ima yok \\
\hline 5 dh & $\begin{array}{l}\text { Donuş̧umlu uygutamul } \\
\text { ve tersıne çevirme } \\
\text { modelı }\end{array}$ & $\begin{array}{l}\text { Gozlemcitel drası } \\
\text { güvenirlik }\end{array}$ & Gờrevden kaçma & $\begin{array}{l}\text { ligi eide cme ik rdemik rstek } \\
\text { oyum }\end{array}$ & Uygulama yok \\
\hline 104 & $\begin{array}{l}\text { Dons, onntus } \\
\text { uygul tmal ir modelı }\end{array}$ & $\begin{array}{l}\text { Gasilemaler tow } \\
\text { gusenirik }\end{array}$ & Gorehdenkxass: & Ahutenuh sel syess & 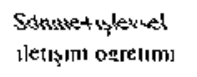 \\
\hline $510 \mathrm{dh}$ & $\begin{array}{l}\text { Jersune f̧es snme } \\
\text { modelı }\end{array}$ & $\begin{array}{l}\text { Gozkinu les ir w } \\
\text { guvenislik }\end{array}$ & Eıkınlıkıen kuçm) & $\begin{array}{l}\text { ligi eld etme nesne elde etme } \\
\text { ik uk muk inck oyun }\end{array}$ & 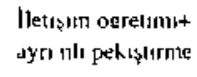 \\
\hline 10 dh & $\begin{array}{l}\text { Don lsumlutu } \\
\text { uytulamil r modelı }\end{array}$ & $\begin{array}{l}\text { Gozlenutler at is } \\
\text { suvenirlit }\end{array}$ & $\begin{array}{l}\text { Ögretın etkınlıgınden } \\
\text { kıçmı }\end{array}$ & 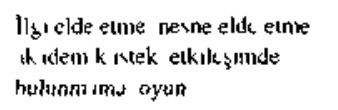 & Ayriml pehş̧ırme \\
\hline
\end{tabular}




\begin{tabular}{|c|c|c|c|c|c|c|c|}
\hline Kayyak & $\begin{array}{l}\text { Dunek } \\
\text { Sayıłı }\end{array}$ & Yuș & Cinsiyet & Öxür Daruma & Probilem Davranıș & $\begin{array}{l}\text { Veri } \\
\text { Toplane }\end{array}$ & Ortan1 \\
\hline $\begin{array}{l}\text { Roberts. Mace } \\
\text { \& Disgstt1. } 1995\end{array}$ & I & 4 & Kaul!n & jlleri dertceute bzüurlü & Kendini yaralamil & $\begin{array}{l}\text { Bì̀tiincül zaman aritilĕ̆ı } \\
\text { kaydı (10 sn) }\end{array}$ & Bunyo \\
\hline $\begin{array}{l}\text { Jwata, Pace, Cowdery } \\
\text { \& Milienberger, } 1994\end{array}$ & 3 & $7.8,12$ & $\begin{array}{l}\text { Frkek (2) } \\
\text { Kadın (1) }\end{array}$ & $\begin{array}{l}\text { Orta ve ilerı derecede } \\
\text { zihin özuirłü }\end{array}$ & Kendini yaralama & $\begin{array}{l}\text { Bulidncul zitman arallišl } \\
\text { kalydi (I0sn) }\end{array}$ & $\begin{array}{l}\text { Terapi } \\
\text { odass }\end{array}$ \\
\hline $\begin{array}{l}\text { [wata, Dorsey, Slifer, } \\
\text { Bauman \& Richman, } 1994\end{array}$ & 9 & 1.18 & $\begin{array}{l}\text { Erkek (8) } \\
\text { Kadin (5) }\end{array}$ & $\begin{array}{l}\text { Orıa ve ileri derecede } \\
\text { zihin özürliı. gelişimsı̀l } \\
\text { gerilik }\end{array}$ & Kendini yaralama & $\begin{array}{l}\text { Bütiincul zanาitr arłalığı } \\
\text { kilydı (10 sn) }\end{array}$ & $\begin{array}{l}\text { Terapi } \\
\text { odisi }\end{array}$ \\
\hline $\begin{array}{l}\text { Zarcone, fwata. Vollmer, } \\
\text { Jagtiani, Smith } \\
\text { \& Maz:ileski. } 1993\end{array}$ & 3 & $26-32$ & Kadin (3) & $\begin{array}{l}\text { Heri derecede zihins } \\
\text { oziirlí }\end{array}$ & Kenclini yartitlama & $\begin{array}{l}\text { Bütüncül zaman aralığı } \\
\text { kidydı ( } 10 \text { ș) }\end{array}$ & $\begin{array}{l}\text { Terapi } \\
\text { odasi }\end{array}$ \\
\hline $\begin{array}{l}\text { Pace, lwatil, Cowdery, } \\
\text { Andree \& Mclntyre, } 1993 \\
\text { serebral palsy }\end{array}$ & 3 & $2,3,7$ & $\begin{array}{l}\text { Erkek (I) } \\
\text { Kadır (2) }\end{array}$ & $\begin{array}{l}\text { Ileri derecede zilhin } \\
\text { üzürlü,görrane özürlü. }\end{array}$ & Kencliui yaralama & $\begin{array}{l}\text { Büitüncijl zaman aralığı } \\
\text { kinydı (I0 sn) }\end{array}$ & $\begin{array}{l}\text { Terapi } \\
\text { odasi }\end{array}$ \\
\hline Durand \& Carr. I99] & 3 & $9.12,12$ & Erkek $(.3)$ & $\begin{array}{l}\text { Orla ve ileri derecedc } \\
\text { zihin ozuritu ve olistik }\end{array}$ & $\begin{array}{l}\text { Kendini yaralama, } \\
\text { saldırgablık, hırçınlık }\end{array}$ & - & Sinff \\
\hline $\begin{array}{l}\text { Iwata. Pace, Kalsher, } \\
\text { Condery \&Cantdo. } 1990\end{array}$ & 7 & $4,5,16$ & $\begin{array}{l}\text { Erkek (2) } \\
\text { Kinden }(5)\end{array}$ & $\begin{array}{l}\text { Hufif, orta ve ıleri } \\
\text { derecede zihis öcurla }\end{array}$ & Kendini yaraliuna & 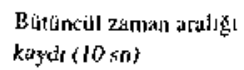 & $\begin{array}{l}\text { Terapi } \\
\text { odasi }\end{array}$ \\
\hline $\begin{array}{l}\text { Sleege. Wacker, Cigrand. } \\
\text { Berg. Novak, Reimers, } \\
\text { Sarso \& DeRand, 1990 }\end{array}$ & 2 & 5.6 & $\begin{array}{l}\text { Erkek (I) } \\
\text { Kadı (I) }\end{array}$ & $\begin{array}{l}\text { Ileri derecede zilhin } \\
\text { özüırlu, çok hzürlü }\end{array}$ & Kendini yaralami & $\begin{array}{l}\text { Parçăalı zaman aralığ l } \\
\text { kaydı }(6 \text { sn) }\end{array}$ & $\begin{array}{l}\text { Bustane } \\
\text { Isunif }\end{array}$ \\
\hline Repp, Felce \& Barton. 1988 & 3 & 6.7 & $\begin{array}{l}\text { Erkek (1) } \\
\text { Kadin (2) }\end{array}$ & $\begin{array}{l}\text { fleri dexecede zihin } \\
\text { özürlïi }\end{array}$ & $\begin{array}{l}\text { Kenditil yaralama, } \\
\text { batsrnakalip darran!ş. }\end{array}$ & $\begin{array}{l}\text { Parçalı zaman aralığ } \\
\text { kaydi ( } 10 \mathrm{sn} \text { ) } \\
\text { anlık zaman ornektemi } \\
\text { day kayd }\end{array}$ & Sinıf \\
\hline
\end{tabular}




\begin{tabular}{|c|c|c|c|c|c|}
\hline Sure & $\begin{array}{l}\text { Araşlırmıs } \\
\text { Mlodelı }\end{array}$ & Guvenurthk & Davranı̧ Işleu & rest Oturumlari & $\begin{array}{l}\text { Davranıs Değtş̧ırme } \\
\text { Tuknoği }\end{array}$ \\
\hline $1525 \mathrm{dk}$ & $\begin{array}{l}\text { Dönuşimlu uygulamal } \\
\text { ve terume çevirne } \\
\text { modeiı }\end{array}$ & $\begin{array}{l}\text { Guzzlemuler ur } n 1 \\
\text { giitrenirl/k }\end{array}$ & Gorevden k «̧nı। & 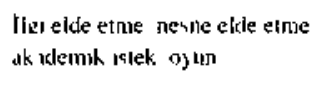 & Ayrım[ı pekılşırme \\
\hline $15 \mathrm{dh}$ & $\begin{array}{l}\text { Dơnuşiımlu } \\
\text { uygulamuldz modelı }\end{array}$ & $\begin{array}{l}\text { Gózlemcilus If dN } \\
\text { ģuvemrlik }\end{array}$ & $\begin{array}{l}\text { Ogretım elkmilı.jnden } \\
\text { kaţıd }\end{array}$ & - & Sonme \\
\hline Is ath & 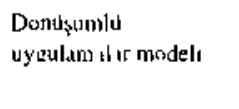 & $\begin{array}{l}\text { Gozfencider ir ma } \\
\text { guvenurlik } \\
\text { uyguldnat guvemirlis=l }\end{array}$ & 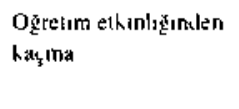 & $\begin{array}{l}\text { HIgı elde etme ikademik isteh } \\
\text { yulnız birakılma oyun }\end{array}$ & Sonme \\
\hline $15 \mathrm{dk}$ & 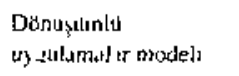 & $\begin{array}{l}\text { Gozlemciles แa } \\
\text { zuvenusjs }\end{array}$ & Gorevden $k$ ıçma & $\begin{array}{l}\text { ligi elde etme akadenik i iek } \\
\text { yalniz birukilma or un }\end{array}$ & Uy gul ina yok \\
\hline $15 \mathrm{dk}$ & 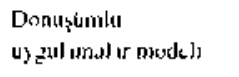 & $\begin{array}{l}\text { Gozlemules "W } \\
\text { żuvens]sh }\end{array}$ & 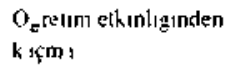 & 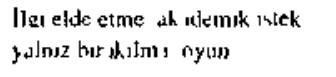 & Sonme \\
\hline $15 \mathrm{dk}$ & $\begin{array}{l}\text { Dönuşumlum } \\
\text { uyğulım ilur model }\end{array}$ & $\begin{array}{l}\text { Gózlenuilcs "IN } \\
\text { guvenurlth }\end{array}$ & Llkınliken haţ̧ma & $\begin{array}{l}\text { Ilgi elde etme akademik istek } \\
\text { y ilniz birakilmu oyun }\end{array}$ & Solme \\
\hline jo Jk & $\begin{array}{l}\text { Tersise yesirme } \\
\text { modelı }\end{array}$ & $\begin{array}{l}\text { GoLkmulkrarass } \\
\text { eivenirlik }\end{array}$ & $\begin{array}{l}\text { Ožretım ethondağinden } \\
\text { kutumd }\end{array}$ & Igl elde etme dhatienik wtek & $\begin{array}{l}\text { laklc vset iletisım } \\
\text { axretımı }\end{array}$ \\
\hline $15 \mathrm{dk}$ & $\begin{array}{l}\text { Donuşamlu } \\
\text { uyeulatmat it modelt }\end{array}$ & $\begin{array}{l}\text { Godemuler ardsi } \\
\text { oftventrlak }\end{array}$ & $\begin{array}{l}\text { Titbib mulud ihdleden } \\
\text { ve górevden kaçmu }\end{array}$ & $\begin{array}{l}\text { Ilgicldk etme ah rdenik isteh } \\
\text { tobly uyguldma yalniz birdkilima } \\
\text { ovun }\end{array}$ & Sönne \\
\hline $10 \mathrm{dk}$ & 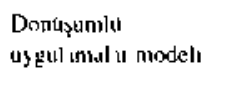 & $\begin{array}{l}\text { Goztemuler arass } \\
\text { guvenurlih } \\
\text { uygul imis suyenirlisi }\end{array}$ & Gótevdlen halyrald & $\begin{array}{l}\text { 1ligi elde elme akddemih sstek } \\
\text { yalmiz birakilma oyun }\end{array}$ & Olumkuz peklįtmme \\
\hline $30 \mathrm{dk}$ & $\begin{array}{l}\text { Tersue gevalue } \\
\text { models }\end{array}$ & $\begin{array}{l}\text { Goslemcilur iris } \\
\text { gävenurlık }\end{array}$ & Lor work den kaţmas & - & $\begin{array}{l}\text { Olumlu ve alumsur } \\
\text { pekışlirme }\end{array}$ \\
\hline
\end{tabular}


YER ALDIĞI ARAŞTIRMALARIN INCELENMESI

\section{KAYNAKÇA}

Asimus, J. M., Wacker. D. P.. Hatding. J., Berg. W. K.. Derby, K. M.. Kocis. E. (1999). Evaluation of anlecedent stimulus parameters for the trealment of escape mainlained aberrant behavior. Journal of Applied B.hurior Anatysis. 32(4). 495-5J3.

Carr. J. E.. Hatfield. D. B., Austin. J. L. \& Bailey. J. S. (1998). Interpreting functional analysis results tring the real-time recording of independent and dependent variables. Behavioral Intervention, 13,61-66.

Carr, E. G. \& Durand. V. M. (1985). Reducing behavior problems througl functional conununication training. Jounal of Applied Behavior Anafysis, 18, 111-126. (Aktaran: Erbaş, 2002).

Chandler, L. K. \& Dahlquist, C. M. \{2002). Fincrional assessment strotegies to prevent and remediate challenging behawior in scholl sestings. New Jersey: Merill Prentice Hall.

Cangelosi. J. (1985). Classroom management strategies: gaining and maintaining sfudents" cooperation. (2nd edition). White Pains. NY: Longman, (Aktaran Chandler, L. K. \& Dahlquist, C. M. (2002). Functional assessinent strategics to prevent and remediate challenging bohavior in scholl settings. New Jersey: Merill Prentice Hiall.).

Cooper, L. J., Wacker, D. P., Brown. K.. McComas, J. J., Peck, S. M., Drew, J.. Asmus J. M. \& Kayser K. (1998). Use of concturrent operants paradigm to evaluate posilive reinforcers during treatment of foot refusal. Beharion Modification. 23(1), 27-38.

Durand. V. M.. (1990). Severe Befiavion Probtems: A fuminat communication training apprach. New York: The Guiltord Press, Inc.

buraml. V. M. \& Carr. E. G. (1995). Functional conmunication training to reduca challenging behavior: Maintanenece and application in now setings. Soimal of Applied Bchatior Anolysis, 24(2), 251-264.

Erbaş. D. (2001). Review of self-mijurious stuties on persons with disabilities. Os $c$ f Egitim Dergisi. 3, 1, 73-84.

Esbus. D. (2002). setisimsel gerifigi olan qocaktarn problem

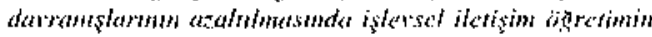

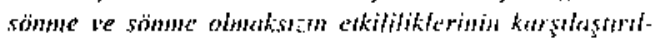
ması. Eskişettir: Anudotı Üniversitesi Yayıłlırı.

Galensky. T. L., Miltenberger, R. G., Stricker, J, M.. Garlinghousc. M. A. \& Koeget. R. L. (2001). Functional assessinent and treatment of meallime helhaviot prothlests.

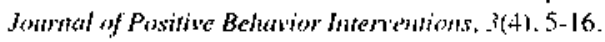

Goh, H.. \& Jwata, B. A. (1994). Behavioral persistence and variability during excinction of self-injury maintained by excape. Jomal of Applicd Behavior Anatisis: 27(1), 173174.

Hagupian, L. P.. Wilsan. D. M., \& Wilder, D. A. (2001). Assessment ind treatment of problem behavior maintained by escape from attention and access to fangible items, Jounal of Applicd Beharior Analysis, 34(2). 229-232.

lwata. B. A.. Pace, G. M., Cowdery, G. E., \& Miltenberger, R. G. (J994). What makes extinction work: An analysis of procedural form and funclion. Somrnal of Applicd Bchavion Analysis, 27(1), 131-144.

Iwata, B. A., Dorsey, M. F., Slifer, K. J., Batlman. K. E., \&. Richınan. G. S. (1994). Toward A functional analysis of self-injury. Sownal of Applied Bcherior Anatysis, 27(2). 197-209.

Iwala, B. A.. Pace. G. M.. Kalsher, M. J.. Cowdery G. E., \& Calaldo. M. F. (1990). Experimental analysis and extinction of self-injurious escape behavior. Joumet of Applied Bethaiour Analysis, 23(1). $11-27$.

Kahng. S. \& iwata. B. A. (1998). Play versus alone condition as controls during functional anajysis of self-injurious excape behavior. Jowmal of Applied Behavion Anatywis, 3/(4). $669-672$.

Keney, K. M., Fisher, W. W. Adelinis, J. D.. \&. Wilder, D. A. (2000). The effects of response cost in the treatment of aberrant behavior maintained by negative reinforcement. Sommat of Appliced Bethorior Analysis: 33(2), 255-258.

Kennedy, C. H., \& Meyer, K. A. (1996). Sleep deprivation allergy symptoms and negatively reinforced problem behavior. Journal of Applied Behavior Analysis, 29(1).133-135.

Kuhn. D. E., DeLeon, I. G., Fisher, W. W . \& Wilke, A. E. (1999). Clarifying an ambiguous functional analysis with matched and mismatched extinction procedures. Journat of Applicd Beharior Anatysis, 32(1), 99-102.

Lalli, J. S. Vollmer, T. R. Progar, P. R., Wright , C.. Borrero, J., Daniel, D. , Barthold. C. H. Tocco, K., \& May, W. (1999). Competition between positive and negative reinforcement in the treatment of escape behavior. Journal of Applied Behaior Analysis, 32(3), 285-296.

Lilli. J. S.. Kales. K., \& Casey, S. D. (1999). Response covariation. Behavior Modificarion, 23(3), 314-4/2.

McComas, J. J., Goddard, C., \& Hoch, H, $(2002)$. The effects of preferred activilies during academic work breaks on lask cngagement and negatively reinjorced destructive behavior. Edacaion and Treatusat of Children, 25(1). $103-112$

McComas, J. J., Hoch, H., Paone, D., \& ElRoy. D. (2000). Escapez behavior during academic lasks: A preliminary analysis of idiosyncratic establisining operations. foumal of Applicd Beharior Anatyis. 33(4), 479-493.

McCord. B. E., lwata, B. A., Galensky. T. L., Ellingson.S. A.. \& Thomson, R. J. (200J). Functional analysis and treatinent of problem behavior evoked by noise. Jotrmal of Applied Bchatior Anotysis, 34(4), 447-462. 
McCord B E Thomson R J \& Iwata B A (200|) Furictional andlysis and treatment of self injury associated uith transitions Journal of Aplict Behan sol Analyus $34(2) 195210$

O Reıliy M F \& Lancion G E (1999) A systematıc analysıs of the unfluence of prot social context on aggression and self injury within anafogue analysis assessinents Behaveor Modification 23(4) 3548

Pace G M lwata B A Cowdery G E Andree P J \& Meintyre T (1993) Stumulus fading during extunction of self injerrous bebavior Journal of Applied Behonsor Atalysis 26(2) 205212

Piazza C C Fisher W W Hanley $G$ P Rcmick M L Contruce S A \& Ailken T L (1997) The use of positive and negative retnforcement in the treatment of escape maintained destruclive behvior Journat of Applied Behavo Analy ws 30( 2) 279298

Plazza C C Moes D R \& Fisher W W (1996) Differentıal remforcement of alternative behnvior and demand fading In the treatment of escape mantamed destruclive behavior Journal of Applied Bchanon Anatysis, 79(4) 569572

Repp A C Felce D \& Barton L E (1988) Basing the trestment of stereolypic and sel injurious behaviors on hypotheses of therr causes Sounat of Appted Bchan wo Anahsts 21 (3) 281289

Rıchman D M Wacker D P Asmus I $M$ \& Carey $S D$ (1998) Functional analysis and extinction of difterent behavior problems exhibited by the same andividual lournal of Applied Behat tor Analysis 3/(3) 475478

Roberts M L Marshall J Nelson J R \& Albers C A (2001) Curriculum based assessment procedure embedded within functional behavoral assessments adentifying escape-motivated behaviors in at geneid education classrom School Psichotog, Rcuen $30(2)$ 264277

Robert, $M$ L Mace $F C$ \& Daggett J A (1995) Prelıminary comparison og two negative in inforccment schedules to reduce self injury $f_{\mathrm{o}} \mathrm{wnat}$ of Applicd Bchavor Analysis, 28(4) 579580

Sieege $M$ W Wacker D P, Cigrand K C Berg W K Norak C O Remers T M Saso G M \& DeRut (1990) Use of negative reinforement in the Irtatment of self injurious behavior lawnat of Appted Betwase Andysis 23(4) 459467
Shrolcy M J Jwatal B A Kanng S Mazaleshı J L \& Lerman D C (1997) Does functional conununication Irdining compete with ongoing contingencses of reinforcement ${ }^{\circ}$ An analysıs during response aç̧ustion and mantan ince Jountat of Applicd Behatom Anabss $30(1) 94104$

Shukin $S$ \& Albin R W (1996) Effects of extunction alone and extinstion plus functional communication training on covarution of problem behaviors Journal of Applied Behavior Analysis 29(4) 565568

Shanner B F (1974) About Behanionsm New York Knopl (Aktaran Durand V M (1990) Severt bethaior problens A juictond communcanon naming spploach New York The Gulford Press Inc)

Sulzer Azarofi B \& Mayer G R (1980) Acheveng Edicats nal Excallence Using behavioral strategies New York Holt Rinehart and Winston (Ahtarat Durand V M (1990) Sercre bchaver problems A funchonal communicaton traming approath New York The Gulliord Press Inc)

Vollmer T R Roune H S Ringdath J E \& M rcus B A (1999) Evalusting treatment challemes with differential reinforcenent of alternative behavior Journat of Apphed Buthom Anahss 32(1) 923

vollmer T R \& Northup J (1996) Functional analysıs of severe tantrums displayed by chiliren with language delays Bchawo Modificamon 20(\$) 2334

Vollmer T R Marcus B A \& Ringdaht J E (1995) Noncontigent escape as treatment for self injurious bchavor matntaned by negative resnforcement Joumat of Applied Behatur Analysis 28(1) 1526

Weehs M \& Gaylord Ross R (1981) Task diffucuity and aberrant behavior in severely handicapped vtuctents Journal of Appled Behanol Analysis 14(1), 1936 (Aklaran Chandler \& Dahlquist 2002)

Zarcone J R Fisher W W \& Prazza C C (1996) Añslysis of tree tıne contingencies as positrve versus negative reinforcement Journal of Apptird Bchatm Analysı 20(2) $247>50$

Zarcone J R Juala B A Vollmer, $T$ R Jaguanı $S$ Smıth $R$ G \& Maralerkı J L (1993) Extincion of self injerious escape behavior with and without insiructional lading Jounal of Applied Behator Analysis 26(3) 353360 